\title{
SIMULATION OF THE HYDRAULIC CIRCUTT OF A WHEEL LOADER BY USING THE BOND GRAPH TECHNIQUE
}

\author{
Gregorio Romero, Jesús Félez, M. Luisa Martínez, J. José del Vas \\ Engineering Graphics and Simulation Group \\ Department of Mechanical and Marufacturing Engineering \\ Universidad Politécnica de Madrid \\ CUosé Gutierrez Abascal No2, CP. 28006, Madrid (Spain) \\ E-mail: \{gregorio.romero; jesus.felez; luisa.mtzmuneta\}@upm.es, jdelvas@industriales.upm.es
}

\section{KEYWORDS}

Bond Graph, hydraulic circuit, wheel loader, vaives, pump, hydraulic cylinder.

\begin{abstract}
Hydraulic systems are widely used in Engineering because they are highly versatile and can be combined with other domains of physics (mechanics, electronics, etc.). For this reason, it is of vital importance to study and develop them with a view to obtaining mechanicalhydraulic systems that are increasingly efficient. The beginning of this paper briefly analyses the method usially used to perform simulation in the hydraulic domain. Subsequently, after performing an analysis of different Bond-Graph technique-based works, different characteristic elements will be individually analysed. Finally, the different elements analysed will be interconnected and a simulation of a hydraulic circuil will be performed in order to obtain a series of results that will enable the different rationales set out in this paper to be validated. Finally, a series of conclusions will be reached based on the work presented.
\end{abstract}

\section{INTRODUCTION}

Hydraulic systems modelling and simulation has been performed using a whole range of techniques, although currently a lot of territory remains to be researched in this area of Engineering. Traditionally, algebraicdifferential equations have been proposed based on the corresponding laws of physics (Cobo et al. 1998.). They bave then been solved in various environments like MATLAB, Simlink, and MAPLE, to name but a few. One of the drawbacks of this procedure lies in the fact that obtaining algebraic-differential equations is usually complex as well as the procedure for solving them, and on many occasions so much time is spent that real time simulation cannol be performed while costs also increase significantly.

Another possible option is to generate the model from zero using specific software, either by the finite elements method, using block diagrams, or using graphic techniques. These types of simulations are often oriented towards specific applications, frequently technological ones, and are therefore mainly focused on obtaining graphic or numerical results (Hydro+Pneu, OHC-Sim, HOPSAN, LVSIM) and move away from obtaining equations for the model.

Although there is still room for it to be improved and optimised in different areas of Engineering, the BondGraph technique (Karnopp et al. 1990), lets a whole range of systems be modelled and then simulated (Gawthrop and Snith 1992; Borutzky and Cellier 1996; Félez et al. 2000). Hydraulic systems can be dealt with in this way, which speeds up the process considerably, and reduces the time needed for modelling and obtaining the algebraic-differential equations. This is reflected in a reduction of process-related costs and an increase in efficiency. It the hydraulic scope of this technique the study has focused on fluid propagation characteristics (Borutzky 1995) or on sirnulating different industrial applications (Bunes and Einang 2000; Kun et al. 1999; Wanli and Fumin 2005,), some of them in combination with other domains such as thermodynamics (Thétiot and Zouaoui 1998). Regarding the simulation of a hydraulic circuit similar to that of the machine in question, some preliminary work has to be done (Krishnaswamy and Li 2006; Nadjm-Tehrani and Strömberg 1999) but the main aim is not the model itself but to optimise and regulate the model.

As can be seen, a lot remains to be researched and improved in the study of hydraulic systems using the Bond-Graph technique. The contribution of this paper to the existing bibliography is that it shows how the different hydraulic parts can be modelled and then connected in order to simulate a wheel loader. To do this, Bondin software (Romero et al, 2005; Romero et al. 2005), is used; It is an enhanced version of another program previously developed (Félez et al. 1990) by one of the authors.

Finally, this paper is iniended to show that it is not always necessary to simulate a specific set of parts at a deternnined instant, which wouldi cause the simulation to be excessively slow. However, it is possible to obtain a series of behavioural laws based on the results of the simulation that will improve computational time. 


\section{VALVES}

As a prior step to developing the different models, apart from other ports that can be used, it should be pointed out that there is an Inertia-type port, and another Capacitor-type port that represent the compressibility of the fluid and its mass, respectively, the values of which are listed below.

- Compressibility:

$$
K=\frac{B}{A \cdot L}=\frac{4 \cdot B}{\pi \cdot D^{2} \cdot L}
$$

\section{B: Bulk fluid module. \\ $D$ : Inside diameter of the pipe section. L: Pipe length.}

- Mass:

$$
I=\frac{\rho \cdot L}{A}=\frac{4 \cdot \rho \cdot L}{\pi \cdot D^{2}}
$$

\section{p: Fluid density. \\ D. Inside diameter of the pipe section. L: Pipe length.}

These equations partly differ from those given by other authors (Rosenberg and Kamopp 1983) as i1 has been assumed there is no defornation in the pipe.

\subsection{Distributor valves}

This type of valve is a hydraulic component designed to let the fluid pass through a pipe, prevent it passing or change its direction in any kind of circuit. They are usually assigned the function of regulating the starting, stopping and change in the direction of movemert of the cylinder rods. Although this is the basic task of these valves they are also used for other functions such as directing the fluid to other valve controls, to the tank discharge or to the manometers, for example.

In these valves the passage of fluid is either total or zero. That is, either all the flow reaches the inlet pipe or none passes through; the same occurs with the outlet pipes.

Classic directional valves, also cailed distributors, can have two, three or more positions, and have two, three or more internal communication circuits. The positions are schematically represented by squares, those with two or three positions being mostly used, while the circuits are indicated by flow lines drawn on the inside of the squares. The arrows on these lines indicate the direction of flow, although in many applications the direction can be opposite to that shown.

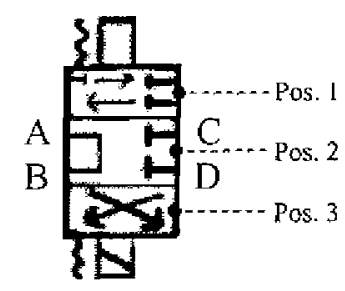

Figure l: Graphic representation of a $3 \times 2$ valve

This valve can be modelled using the Bond Graph technique by representing in a single model the different internal communication circuits between the differen! inputs $(A, D)$ and outpuls $(B, C)$, ard then fitting in as many resistances as are needed to configure the different positions.

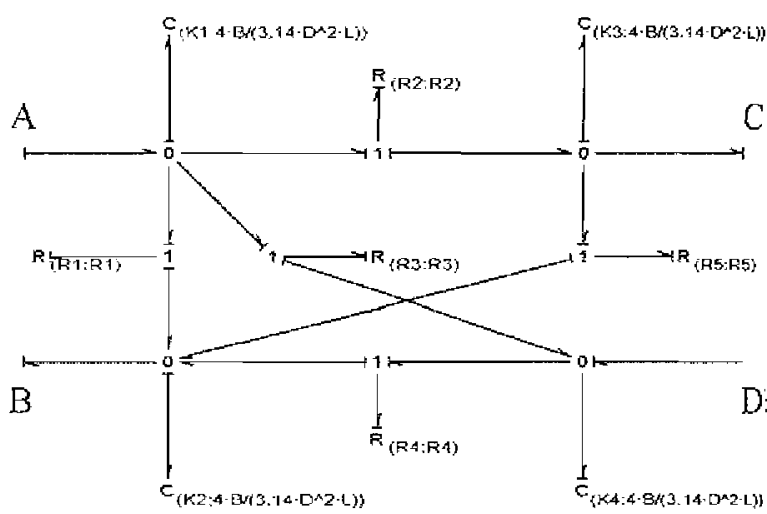

Figure 2: 3x2 valve nodel using Bond-Graph.

In the above figure the assembly of the valve model to the rest of the model or other elements would be done through the bonds at the ends $(A, B, C, D)$.

The $\mathrm{C}$ capacitor ports represent fluid compressibility and must be placed so that the causality in the type $R$ ports is appropriate. The type $\mathrm{R}$ ports are entrusted with ensuring the fluid passes one way or another by means of its value. All of them carry effort causality on the port with the purpose of defining the effect on the flow. they let pass, since it is verified that:

$$
Q=\frac{P}{R} \Rightarrow\left\{\begin{array}{l}
\text { Si } R \downarrow \Rightarrow Q \uparrow \\
\text { Si } R \uparrow \Rightarrow Q \downarrow
\end{array}\right\}
$$

In the above expression P stands for the effort existing in the bond that reaches port $\mathrm{R}$. therefore, depending on the difference of efforts port $R$ defines the flow that passes through the communication circuit. If $R$ has a very low value an open pass is being simulated, while if it is very high, the pass is closed, as the flow defined by the resistance port will tend to zero. Thus, by controlling the value of $R$, the flow passing through each valve circuit is also controlled, which means the behaviour of a valve of this type is being simulated.

The type $\mathrm{R}$ ports are associated with type I junctions to be able to define the flow volume that will flow through 
the rest of the bonds, and since the 1 junction is of this type the flow volume will be maintained. However, the C ports are associated with type 0 junctions since they indicate a loss of volume.

Below is the code used to change the different positions of this type of valve.

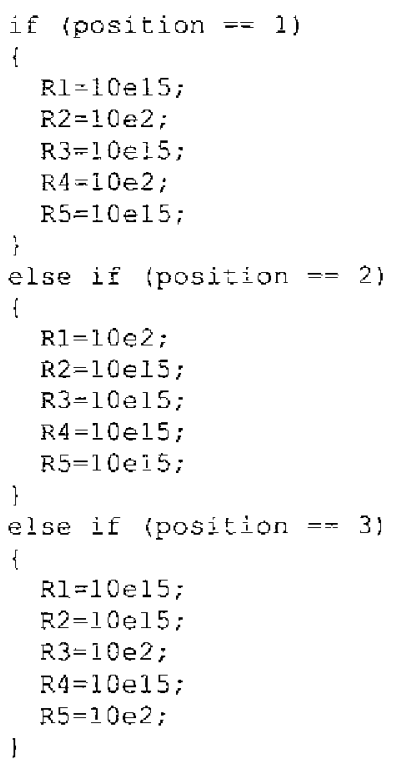

\subsection{Non-return valve}

This type of valve is capable of letting the fluid pass in one direction but not in the opposite direction. It is closed by using spherical, conical or plane seats, accompanied by a return spring that obliges the fluid flowirg in the free direction to overcome a minimum pressure, almost always of a small value, to be able to produce the opening.

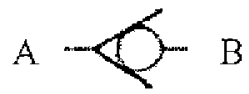

Figure 3. Graphic representation of a non-return valve

In the Bond-Graph technique this type of valve can be modelled by placing a type $\mathrm{R}$ port between the input and the output to let the fluid pass in one direction but not in the opposite direction and by placing a type 1 port to determine the direction of flow and thus be able to govern the value of resistance $R$.

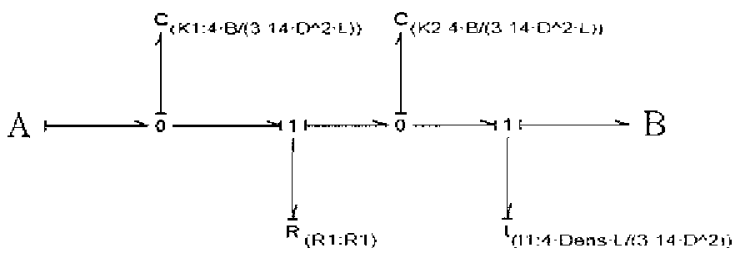

Figure 4: Non-retum valve model using Bond-Graph.

As with the previous valve a type $R$ port must be nserted to let the fluid pass or not. In the above figure, when the volume goes from left (A) to right (B), the value of resistance $R$ must be very low (only the value of the fluid load loss as it passes through the valve) in order to let the fluid flow freely, while if the direction of volume is reversed (from right to left) the value of $R$ must be high so that no volume can fiow.

In order to define the flow volume communicated to the rest of the model the causality needs to be of effort on the $\mathrm{R}$ ports. This is achieved by adding two type $\mathrm{C}$ ports to represent fluid compressibility. It is also necessary to add a type 1 port to represent the fluid mass that is in motion. Because this latter port is causality of flow on this port, inserting it causes the causality of the bond at point $A$ to be the same as at point $B$, thus causality is not changed on the route.

Therefore, the direction of flow of the fiuid can be determined either by the flow of the type 1 port or by comparing the efforts existing in the type $C$ ports. Thus, the direction of volume will be positive providing the inertia flow is positive or when the effort in the first capacitor is greater than in the second one.

Shown below is the code used to change the value of the type $\mathrm{R}$ port automatically.

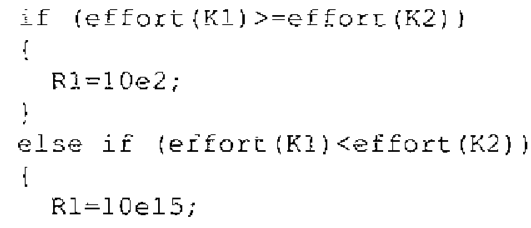

As can be seen, when the effort at the right is greater than the effort at the left the fluid tries to flow from right to left and its passage is prevented due to the high values assigned to $R$, while if the effort at the left is greater than the effort at the right, passage is allowed, with value $R$ being the corresponding load loss through the valve.

\subsection{Pressure limiter valve}

Pressure limiter valves control the maximum pressure in the circuit by means of an electrical input signal that is proportionally converted into a pressure on the fluid.

According to figure 5, the fluid should logically pass from point A to point B. However, under conditjons of overpressure in the circuit (point B) the valve opens and lets the fluid go directly to point $\mathrm{C}$, that is, the tank. By this means, the maximum pressure at point $B$ of the circuit is limited.

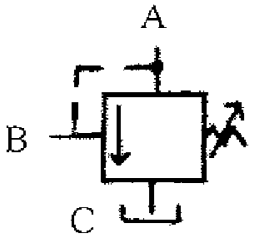

Figure 5 : Graphic representation of pressure limiter valvo 
To make the simulation model in a Bond-Graph the three branches have to be inserted; one input (A) and two outputs $(B, C)$, and a type $R$ port inserted to let the fluid pass or not to the tank branch (C), where the pressure is zero. The value of this $\mathrm{R}$ port will depend on the effort existing in the bond node of the three branches, which means an additional port needs to be inserted in order to determine it. This other port is a type $\mathrm{C}$ port and represents fluid compressibility; on the other hand it serves to make the causality in the type $\mathrm{R}$ poris the appropriate type and on the other hand allow obtaining the pressure related to the compression of the fluid.

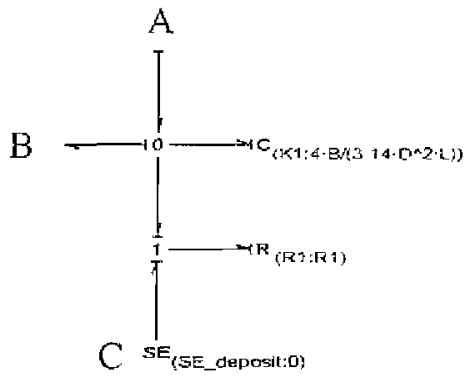

Figure 6: Pressure limiter valve model in Bond-Graph.

In the above figure the type $\mathrm{R}$ port regulates the volume crossing the branch over which it is placed. Therefore, if the value of $R s$ very high all the volume entering through branch $\mathrm{A}$ leaves through branch $\mathrm{B}$, and as a result the limiter valve is closed. To the contrary, if the pressure in the circuit (branch B and logically branch A, in which exist the same pressure) reaches a maximum value, the value of $R$ needs to be a minimum so as to let all the volume pass to the tank branch (C).

Shown below is the code used to change the value of the type $\mathrm{R}$ port automatically depending on the maximum value of the pressure.

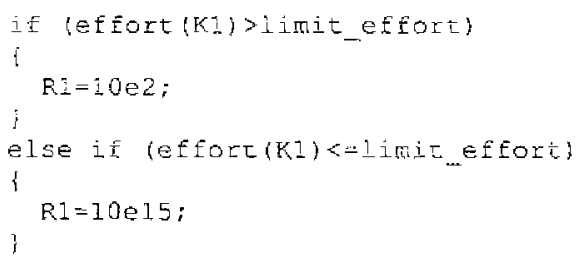

It can be seen that when the effort in the capacitor is greater than a maximum value the valve opens (effort $(K l)>$ limit_effort) and if that is not the case, it closes (effort $(K 1)<=$ limit_effort $)$.

\subsection{One-way tlow limiter yalve}

The main purpose of the valves regulating volume or flow is to control the amount of fluid sent to the actuators or working parts. When constant flow pumps are installed in the circuit, the maximum volume flowing through a circuit can never be more than what the pump is capable of generating, which means the flow regulators usually limit the volume to this value sending the rest of the fluid to the tank.

This type of valve can regulate the flow either in one direction or both. In this case, a valve that regulates flow in one direction but not in the other will be described.

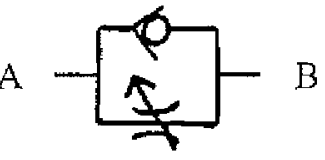

Figure 7: Graphic representation of a one-way flow limiter valve

It can be modelled in a Bond-Graph by placing the two branches in parallel, each with its type $\mathrm{R}$ ports between the input and the output to regulate the passage of flud: The $\mathrm{R}$ port placed in the upper branch must let all the fluid pass in one direction (from $A$ to $B$ ) and prevent it from doing so in the opposite direction (from B to A), while the task of the port placed in the lower branch will be to regulate the volume passing through the valve when the fluid is circulating in a particular direction (from $\mathrm{B}$ to A).

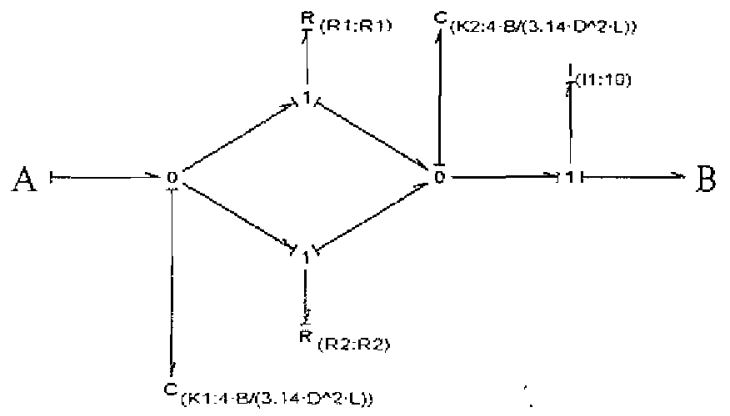

Figure 8: One-way flow liniter valve model in Bond-Graph.

As with the non-return valve, the direction of flow can be determined by inserting a type i port to represent the fluid mass that is in motion or by comparing the efforts existing between the input and the output.

According to the above figure, port $R 1$ represents the non-return and port $R 2$ represents the narrowing. Thus, if the direction of flow is from $A$ to $B$, resistance $R$. must have a very low value so the fluid can pass to that branch instead of passing through the other (resistance R2), thereby not producing any narrowing whatsoever. If the direction of flow is from $B$ to $A$, resistance $R$ l must have a very high value to make the fluid pass through the other branch (resistance R2) and so produce the load loss in the narrowing.

Ports $\mathrm{Cl}, \mathrm{C} 2$ and $\mathrm{ll}$ are built into the model to make the causality appropriate in each of the $R$ ports, and $s 0$ regulate the volume circulating depending on the direction of flow of the fluid. The port values are those seen in the other models, with the exception of the II port, which in this case has a low value as its purpose is to obtain appropriate causality in port R1, as well as to impose the conditions governing the values of the $R$ 
ports.

In order for this type of valve to function properiy the code needed is shown below, where what has been explained above can be clearly seen:

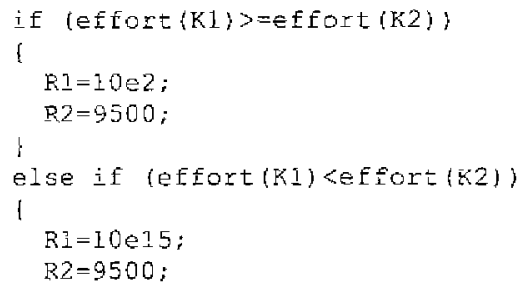

Therefore, when the flow of the type 1 port is positive I $($ flow $(I)>=0$ ) the fluid circulates from $A$ to $B$ without any narrowing since the fluid can flow freely through the upper branch, while when the flow is negative, (flow $(l l)<0$ ) narrowing occurs when the fluid is made to flow through the lower branch.

\section{HYDRAULIC CYLINDER}

Cylinders are the working parts of hydraulic circuits that are most frequently used in machines. Using the flow and pressure provided by the pumps the work is developed in these parts through a straight-line forward and backward movement that takes place in the different phases of a cycle.

However, they can be classified into two types: simple acting and double acting. The first of the two types uses the force from the hydraulic circuit to carry out one of ihe movements, and an external force like that due to the action of a spring or to the force of gravity to carry out the opposite movement. The second type uses hydraulic force to effect both movements, whether or not helped by external forces.

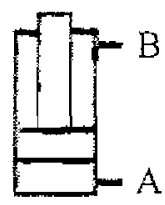

Figure 9: Graphic representation of a hyobaulic cylinder.

In a Bond-Graph, a hydraulic cylinder is modelled by initially putting in place the inpul and output branches and then the mechanical forces appearing on the piston rod, which in figure 9 are the weight and the friction between the cylinder and its housing. It is important to bear in mind that two domains are being worked in, hydraulics and mechanics. This means that hydraulic power has to be transformed into mechanical power and vice-versa, using two TF elements placed at the input and output of the cylinder.

In figure $I 0$ the $\mathrm{KJ}$ port placed next to input $\mathrm{A}$ represents fluid compressibility and also has the task of making the causality in port $\mathrm{R} 1$ be of flow entering the system. This causality must be so because this port will define the limits of the piston displacement ( $\max$ and Lmin), so that when the piston reaches the ends, value R1 is very high and so interrupts the fluid flow. To obtain the distance run by the cylinder from its initial position a type 1 port has been assigned to it, over which, in addition, the effect of gravity appears.

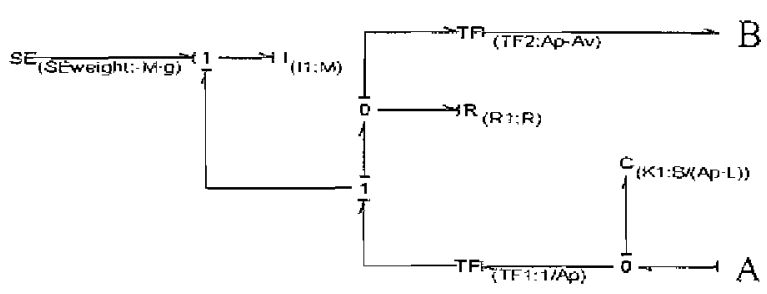

Figure 10: Fydraulic cylinder model in Bond-Graph

Regarding the TF elements, the one placed at the beginning of the distance displacement serves to transform the bydraulic domain variables to the mechanical domain by using the piston area $(A p)$, while the one placed at the end serves to make the opposite transformation by taking the piston area less that of the piston rod $(A p-A v)$.

\section{PUMP AND ENGINE}

An engine is an element belonging to the field of rotational mechanics that transforms one kind of energy, either electrical, thermal or hydraulic into mechanical energy at the output shaft. From a Bond-Graph point of view it is represented as a flow source in units of radians/second, regardless of the type of engine, as we are dealing with an angular velocity source.

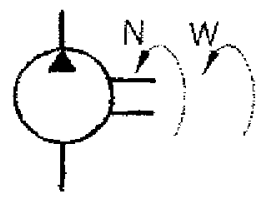

Figure 11: Graphic representation of a hydraulic pump.

As for bydraulic pumps (fig.11), they are an element, which after being driven by an engine to an angular velocity $\omega$ with a torque $N$, generates a flow $Q$ of fluid under a specific pressure $P$. The basic characteristic of a hydraulic pump is its cylinder capacity per rotation, which defines the volume of fluid generated by each rotation of the pump shaft. In the Bond Graph technique these are represented by a TF type element, whose ratio is the cylinder capacity per rotation, and it is this that makes the change from the physical domain of rotalional mechanics (input) to the hydraulic domain (outpul). It is then connected to the inpul and output branches using a type I node, by means of which the flow volume of both branches will be maintained but not the pressure, which at the input is atmospheric 
pressure and at the output is the input pressure plus the pressure contributed by the pump.

\section{HYDRAULIC CIRCUIT OF THE MACHINE}

The mission of a wheel loader's hydraulic circuit is to distribute the flow volume and pressure supplied by the pumps to the different hydraulic cylinders. Due to the work developed through the straight line forward and backward movement that takes place in the different phases of a cycle, these cylinders are responsible for loading and unloading the material as well as rotating the machine. The circuit comprises an oil tank, two pumps whose job is to dive the flow through the whole circuit, different distributor, non-return and pressure limiter valves, filters and bydraulic cylinders, as may be seen in the following figure.

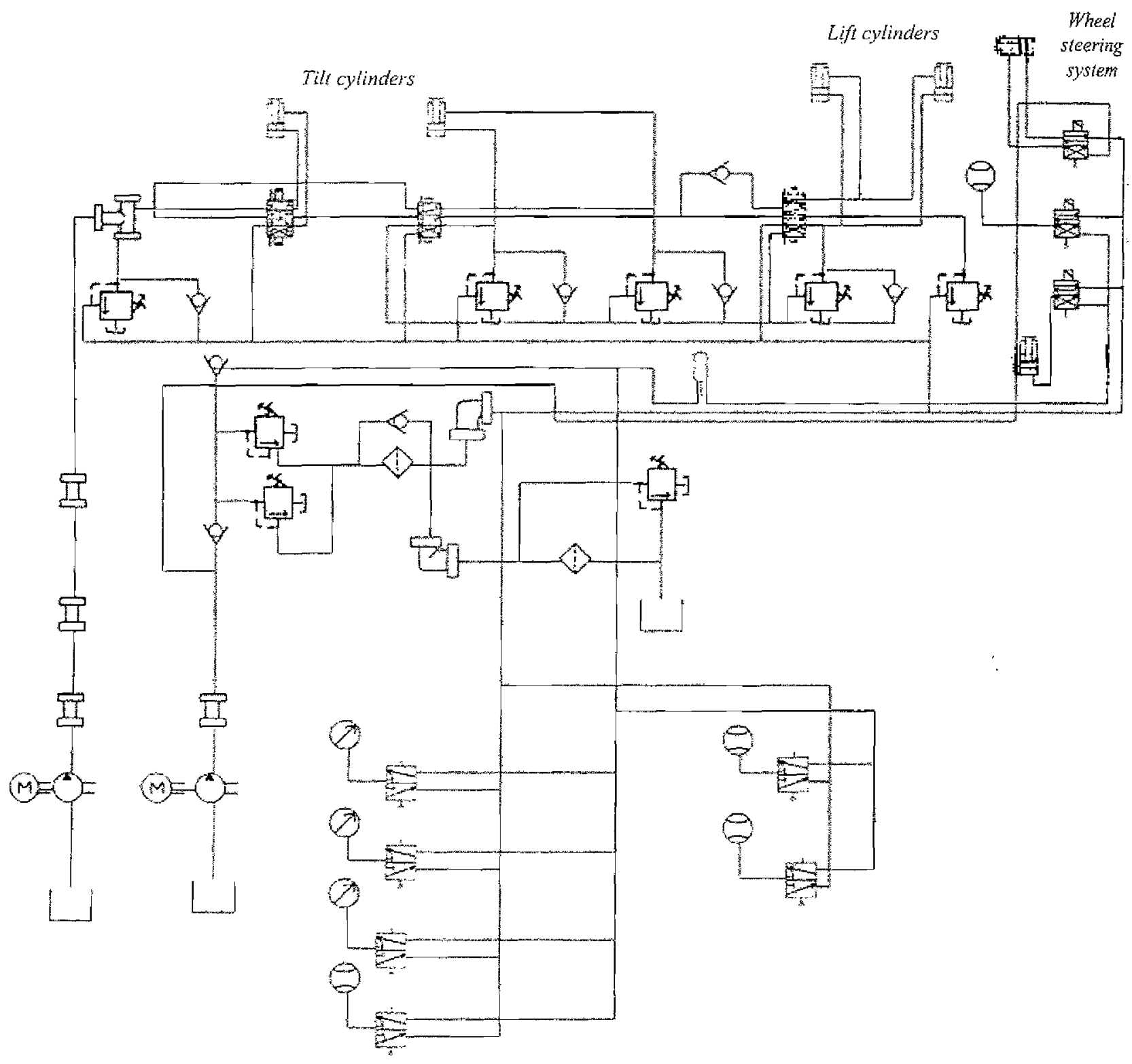

Figure 12: Wheel loader hydraulic circuil model with Bondin sotware.

The hydraulic circuit shares common elements of the system entrusted with producing the vertical movement of the bucket and the loading and unloading system, thereby allowing the corresponding actuators to function simultaneously and move in one direction or the other by means of the different distributor valves.

In addition to the elements mentioned throughout this paper, type R elements have been included in order to be able to simulate the secondary losses due to the fluid circulating through the pipe, the elbows and the joints.

$$
R=8 \cdot \rho \cdot \xi \cdot \frac{Q}{\pi^{2} \cdot D^{4}}
$$

$\xi$ : Coefficient of secondary losses in each element.

Q: Flow. 


\section{RESULTS}

In the simulation, the pipe sections have been deemed to have a constant diameter of $8 \mathrm{~cm}$ and the engine moving line pumps to have linear acceleration during the first 0.5 seconds, the instant at which a constant speed of 350 $\mathrm{rad} / \mathrm{s}$ is reached, corresponding to the supply of a 2 litre per second flow rate.

The simulation lasts for 20 seconds. In the first half of the time the cylinders will be moved in one direction and in the other half, in the opposite direction. It must be said that because the displacements of the lifting and bilting systems have different limits, the cylinders of both systems will not move in unison during the whole sycle.

Figures 13 and 14 show the movement of the cylinder responsible for producing the vertical movement of the bucket and the cylinder responsible for loading and unloading, respectively.

Ginder displacemen $[\mathrm{m}]$

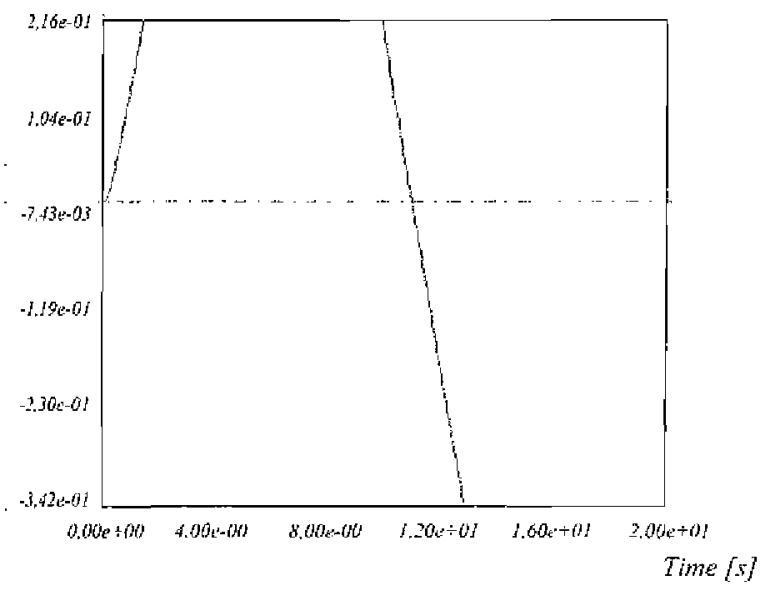

Figute 13: Tilting cylinder. displacement

Oylinder displacement [m]

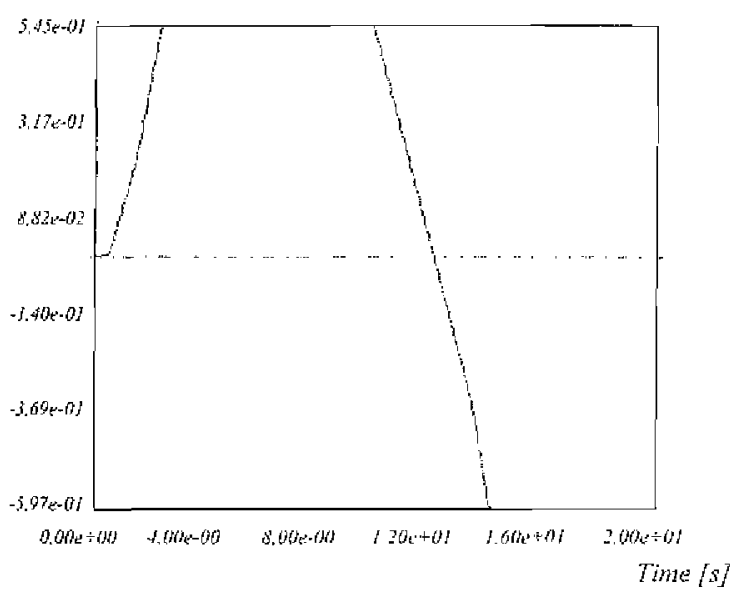

Figure 14: Lifting cylinder dispiacemenc.

In figure 13, it can be seen how the rod moves in a linear form practically from the beginning until it reaches the limit of its displacement, and then starts to move again when the direction of circulation of the fluid is reversed. Although the pump continues to supply flow, the cylinder stops in both cases, as when it reaches the limit of its displacement the pressure limiter valve comes into operation.

In figure 14, it can be seen how the rod also moves in a linear form practically from the beginning until it reaches the limits of its displacement. It can also be seen how the lifting cylinder movement undergoes a change in gradient approximately after the first second. This is because the other cylinder, the tilting cylinder, has concluded its displacement and therefore all the flow driven by the pump is ased to move only the cylinder represented.

In order to better understand the previous two graphs, the speed of the tilting cylinder has been represented where it can be seen how the cylinder speed becomes constant almost from the very moment the cylinder begins to move in one direction or the other, and how the speed is zero when it reaches the end of its displacement (fig. 15).

Ginder speed $[\mathrm{m}]$

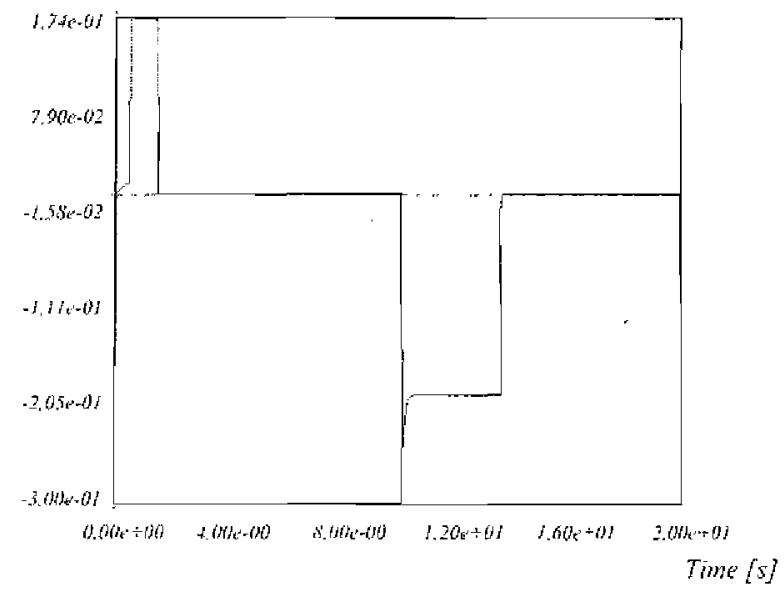

Figure 15: Tileing cylinder rod speed.

Colinder speed $[\mathrm{m}]$

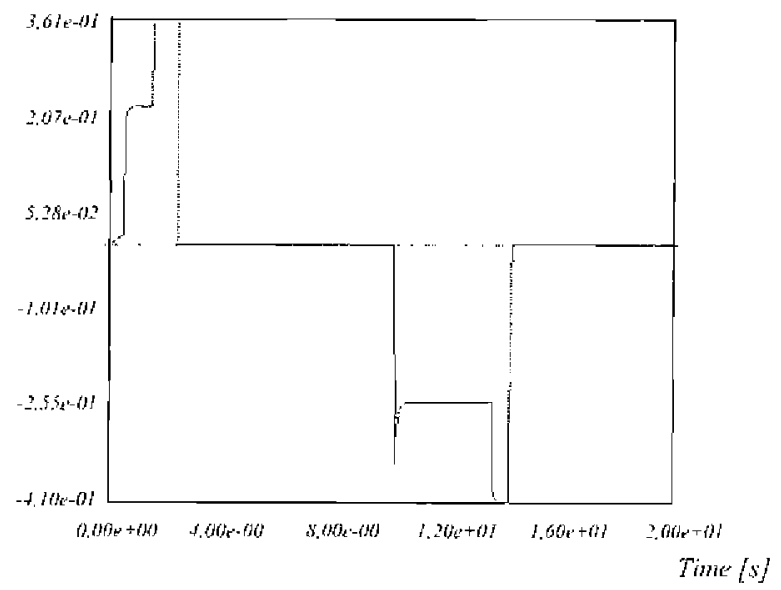

Figure 16: Lifting cylinder rod speed. 
Likewise, figure 16 shows the lifting cylinder speed where it can be seen that when the tilting cylinder has stopped its speed accelerates because the fluid was previously distributed through both cylinders but is now only distributed through one.

When a complete simulation of all the hydraulic circuit has been performed the behaviour of the different cylinders can be analysed from the different results obtained. In this way an expression can be found to determine the speed of the different actuators as a function of the different control inputs (fig. 17).

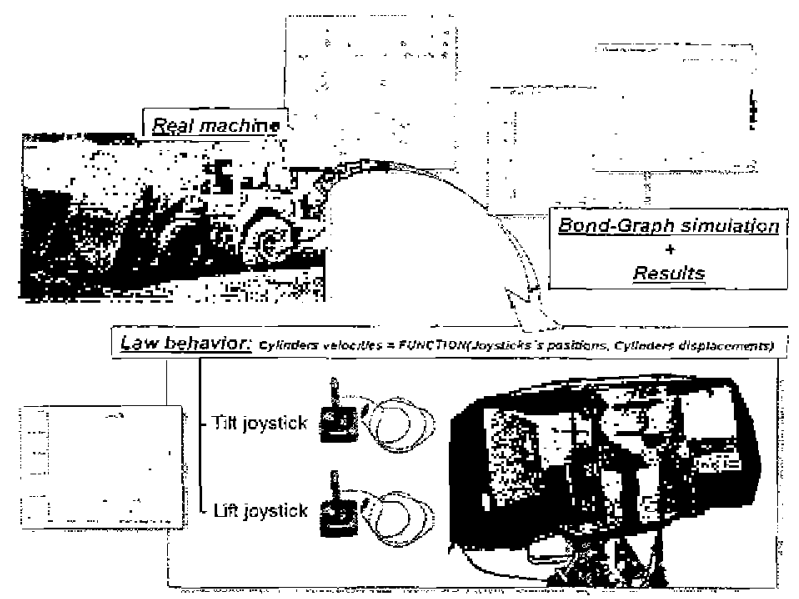

Figure 17: Outline of how behavioural law is oblained.

Therefore, instead of proceeding to perform a simulation of the full circuit it is enough at any instant to implement these expressions to obtain the movement of the bucket (Romero et al. 2006).

These expressions can be written simply as,

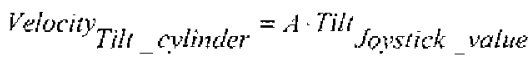

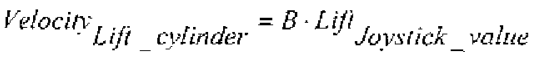

where $A$ and $B$ are constants that are dependent on the corresponding cylinder being out of the limits of not, and if the other cylinder is moving at the same time or not.

\section{CONCLUSIONS}

Various models of elements developed by the Bond Graph technique have been presented. The validity of these models is evident from the models themselves and the simulations performed. A complex model has also been developed by "encapsulating" various sub-models prepared beforehand. In conclusion, it may be said that in simulations that need a real time solution, a full simulation of the entire hydraulic circuit can be performed, and then the model can be simplified by just analysing the different results obtained. Next one or more expressions can be obtained to determine the speed of the different actuators as a function of the inputs.

\section{REFERENCES}

Borutzky, W. 1995. "Discontinuities in a Bond Graph Framework". Joumal of the Franklin Institute, Elsevier Science Ltd, Vol. 332B, No. 2. pp. 141-154.

Borutzky, W. and Cellier, F. 1996. "Tearing in Bond Graphs with Dependent Storage Elements? Proceedings. of CESA'96, pp. $1113-1119$

Bunes, O. and Einang, P.M. 2000. "Comparing the performance of the common rail fuel injection system with the traditional injection system using computer aided modelling and simulation". ENSUS 2000, International Conference on Marine Science and Technology for Environmental Sustainability. Newcastle.

Cobo, M. et al. 1998. "Modeling, Identification and real-time control of bucket hydraulic system for 1 Wheel type loader earth moving equipmene". Joumal Mechatronics vol. 8. pp 863-885.

Félez, J. et al. 1990. "Bondyn: A Bond Graph based sirnulation program". Trans. ASME. J. Dyn. Sys. Measurement and Control. Vol.112, pp.717-727.

Félez, J. et al. 2000. "Deriving simulation models from bond graphs with algebraic loops. The extension to multibond graph systems". Joumal of the Franklin: Institute. Vol. 337 , pp.579-600.

Gawthrop, P.J. and Smith, L.S. 1992. "Causal augmentation of Bond Graphs with algebraic loops". $J$ of the Franklin Institute. Vol. 329, No.2, pp.291303.

Karnopp, D.C. et al. 1990. "System Dynamics: A Unified Approach". John Wiley \& Sons, Inc., Second edition.

Krishnaswamy, K. and Li, P.Y. 2006, "Bond Graph Based Approach to Passive Teleoperation of a Hydraulic Backhoe". Transactions of the ASME. Joumal of Dynanic Systems, Measurement and Control. Vol, 128. pp 176-185.

Kun, D. et al. 1999. "Simulation Study on the Hydraulic Jacking systern for LLAOHAI2 Platform". Proceedings of the 3rd International Symposium on Fluid Power Transmission and Control (ISFP'g9). Beijing. International Academic Publishers. pp 1822.

Nadjm-Tehrani, S. and Strömberg, J.E. 1999. "Formal Verification of Dynamic Properties in an Aerospace Application". Journal Fomal Methods in System Design, Springer Netherlands. Vol. 14. N2. pp 135 169.

Thétiot, R. and Zouaoui, F. 1998, "Automatic Construction of Processes from a Bond Graph Representation". Qualitative Reasoning Group research QR-98. Northwestern University. pp 131136.

Romero, G. et al. 2005. "Optimised procedures for obtaining the symbolic equations of a dynamic system by using the Bond-Graph technique". Internationd Conference on Bond Graph Modeling and Simulation ICBGM'05. New Orleans. SCS Publishing, Simulatign Series. Vol.37, No.1, pp.51-58. 
Romero, G. et al. 2005. "Systematic reduction of dynamic equations to a minimal set in systems modelled with Bond Graphs". International Conference on Integrated Modeling and Analysis in Applied Control and Automation IMAACA 05. Marseille. pp.59-65.

Romero, G. et al. 2006. "Kinematic analysis of mechanism by using Bond-graph language". European Conference on Modelling and Simulation ECMS 2006. Bonn . pp [55-165.

Wanli, L. and Fumin, Z. 2005. "Analysis on Dynamic Characteristic of a High-pressure Water Generator". Sixth International Conference on Fluid Power Transmission and Control (ICFP' 2005). Hangzhou.

Website of Hydro+Pneu software. $<$ htp $/ /$ www preuhydro.con/ $>$

Website of Software for Fluid Power Technology. <http://joumal.fluid.power.net/issue6/sofware6.html >

Website of Linköpings Universitet. $<$ http://www.flumes.ikp.liu.sc/tools/hopsan/index_en.xf/>

Website of Lab-Volt Systems, Inc. $<$ http://www.labvoit.com/display_left.cfm?view=Topics >

\section{AUTHOR BIOGRAPHIES}

GREGORIO ROMERO received his Mechanical Engineering and Doctoral degrees from the UNED. (Spain) in 2000. He got his $\mathrm{PhD}$ Degree from the Technical University of Madrid in Spain in 2005 working on simulation and virtual reality, optimizing equations systems. He has worked as Assistant Professor at the Technical University of Madrid in Spain (UPM) since 2001. He is developing his research in the field of simulation and virtual reality including simulation techniques based on bond graph methodology integrating computer graphics and virtual reality techniques to simulation in real time. He has published more than 35 technical papers and has been actively involved in over 20 research and development projects and different educational projects.

JESÚS FÉLEZ received his Mechanical Engineering and Doctoral degrees from the University of Zaragoza in 1985 and 1989. He started as Associate Professor at the Technical University of Madrid in Spain (UPM) in [990 and became Full Professor in 1997. His main activities and research interests are mainly focused on the field of simulation, computer graphics and virtual Jeality. His research inciudes simulation techniques based on bond graph methodology integrating computer graphics and virtual reality techniques, mainly iddressed towards the development of simulators. He has published over 50 technical papers and has been ictively involved in over 25 research and development projects. He has served as thesis advisor for 30 master's theses and four doctoral dissertations.

M. LUISA MARTÍNeZ received her Mechanical Engineering and Doctoral degrees from the Technical University of Madrid (Spain) in 1990. She got her PhD Degree in 1997 working on variational geometry. In
1990 she started to work as Associate Professor at the Technical University of Madrid in Spain (UPM), Her thesis was focused on variational geometry. She usually works in the field of computer graphics, virtual reality and $\mathrm{CAD}$. During this time she has been involved in different educational projects and pilot activities promoted by the European Commission and other Spanish institutions. She has published over 40 technical papers and has been actively involved in over 25 research and development projects.

JUAN JOSÉ DEL VAS received his Mechanical Engineering degree from the U.P.M. (Spain) in 2006. He has worked as researcher at the Technical University of Madrid in Spain (U.P.M.) since 2005. He developed his research in the field of simulation techniques of systems based on bond graph methodology and in environmental projects. He has been involved in others technical papers. 